\title{
Women's recovery journeys from Chronic Fatigue Syndrome towards wellbeing: A creative exploration using poetic representation
}

\author{
Mahima Kalla · Margaret Simmons
}

\begin{abstract}
Chronic Fatigue Syndrome (CFS) is a poorly understood condition, with an unclear aetiology. Due to diagnostic difficulty, CFS has frequently been dismissed by medical professionals as an untreatable "psychological issue" leading to patients not receiving adequate care for extended periods of time. This situation has led to patients feeling isolated, neglected, and misunderstood. CFS is more common in women than men, in an approximate ratio of 4:1; accordingly, we explore seven (7) women's experiences of CFS and by adopting an idiographic approach seek to amplify the voices of a group of patients who have long been marginalized, and often dismissed. Findings are presented using a narrative research technique called poetic representation, wherein participants' interview transcripts are cast into poetic forms. The condensed encapsulation of participants' experiences through carefully crafted poetry adds an intensity that focuses readers' attention more tightly than merely telling their stories. A small sample size commensurate with the study's aim, enabled an in-depth exploration of each individual's experiences. In the context of CFS, themes surrounding illness, diagnosis, treatment, wellbeing, and recovery were explored, focusing particularly on the potential for the recovery of a new life achieved through participants' self-agentic psychosocial endeavors. The emerging poetic representations were clustered together in themes using a temporal framework, as follows: 1) Downhill to diagnosis; 2) From diagnosis to despair; 3) From despair to hope; 4) Looking back to move forward; 5) And, now. This research not only sheds light on the experiences of a puzzling illness, but also seeks to drive improvements in patient care through a more authentic understanding of the CFS lived experience.
\end{abstract}

Keywords: Chronic Fatigue Syndrome, CFS, myalgic encephalomyelitis, women's health, chronic disease, poetic representation, poetic inquiry, wellbeing, creativity, qualitative research

\section{Introduction}

Myalgic encephalomyelitis/Chronic Fatigue Syndrome (ME/CFS) (hereafter referred to as CFS) is a debilitating condition, with an unclear pathophysiology and no conclusive diagnostic options (Sweetman et al., 2019). CFS symptoms include enduring fatigue, muscular pain, sleep disruptions, and emotional difficulties (Sweetman et al., 2019; Larun \& Malterud, 2007; Söderlund et al., 2000). While the pathophysiology of CFS is currently unclear, recent research has shown that CFS is characterized by severe immunological malfunction (Sweetman et al., 2019). Currently, CFS diagnosis occurs primarily through a process of elimination of other illnesses with similar symptomatology assessed against patients' self-reported symptoms (Sweetman et al., 2019). There are over 20 clinical definitions of CFS, which makes it difficult for health practitioners to appropriately identify and treat the condition. A lack of clarity about the specific biomarkers for CFS renders patients and families confused and often without adequate 
health and social care potentially for long periods of time (Sweetman et al., 2019). While people of all ages and socio-economic groups can be impacted by CFS, research suggests that CFS occurs more commonly in women, with female-to-male CFS incidence ratios reported to be between 2:1 and 6:1 (Sweetman et al., 2019; Larun \& Malterud, 2007).

When faced with a health condition such as CFS that could conceivably last a lifetime, patients are forced to incorporate their illness into their daily lives, and achieve some semblance of wellbeing in the midst of a complicated illness experience. As CFS sufferer Cornes (2011) explains, the illness is hard to describe, may be viral or flu-like, is dominated by chronic exhaustion and is a state where "sickness has become the new normal" (p. 342). This state of being with CFS is one of remission rather than restitution (Frank, 2013). Moreover, there is ambivalence around what a normal or regular life entails for those with chronic illness. With acute illnesses, there is often a restitution or return to pre-illness levels of health - but not so with chronic conditions which necessitate ongoing adjustment, acceptance and management. Indeed, with illnesses such as CFS, there is often a more dynamic, spiraling recovery journey towards improved states of wellbeing - as Frank (2013) describes it - a 'remission'.

While there is no globally recognised singular definition of wellbeing, there is some consensus among scholars that wellbeing is a multi-faceted concept, driven by individuals' unique preferences and values in life (Eger \& Maridal, 2015). The knowledge and discourse of wellbeing has evolved over centuries, from a relatively simple concept, considered interchangeably with "happiness", to a contemporary holistic field of inquiry concerned with the study of overall quality of life and life satisfaction (Eger \& Maridal, 2015). Eger and Maridal (2015) posit that wellbeing has two main facets: happiness (that is emotional, sensory, and affectbased in nature), and life satisfaction/livability. McNaught (2011) also presents a multidimensional framework of wellbeing which comprises elements associated with the individual (e.g. physical, spiritual, psychological), the family (physical safety, ecology, economic resources), and the community (e.g. identity, fairness, equity). In her work on the 'wellbeing machine', McLeod (2017) discusses the notion of 'becoming authentic', and the transformative possibility of illness, whereby new ways of being become possible. She suggests that through improved affective states, such as hope, joy, trust and excitement, 'recovery' can be made possible. The discourse on recovery has expanded in recent decades to suggest that a person may be able to recover from illness and "recover a life" (Slade et al., 2014, p. 14) despite not being fully medically 'cured' (Anthony, 1993).

The notion of recovery too, is multi-dimensional, going beyond the cessation of symptoms or a search for cure, to encompass the achievement of holistic outcomes and enhancement of a patient's overall wellbeing and quality of life (Harvey \& Ismail, 2008). Recovery may represent different things for different people (Harvey \& Ismail, 2008). It may entail improvement in the overall quality of a patient's life, improved social relationships, greater self-efficacy, ability to engage in meaningful economic activity, or the general ability to lead personally fulfilling lives (Liberman \& Kopelowicz, 2005; Mueser et al., 2002). Some even view recovery as the journey from a lack of hope or purpose in the context of an illness or disability, to a more enriched and satisfying life experience (Secker et al., 2002). Developments such as gainful employment may be seen as milestones on the recovery journey, rather than an end goal that one reaches upon a final recovery. Indeed, recovery is a non-linear evolving journey, an "ongoing experience" (Secker et al., 2002, p. 415), and sometimes characterized by relapses. Nevertheless, in the pursuit of recovery, patients may be assisted to experience greater personal wellbeing and to lead more satisfying lives. 
In light of the personalized nature of wellbeing and recovery, the exploration of patients' personal narratives becomes even more critical in the context of a confounding illness such as CFS. Patients often look to the health care system for information and support amid what may be a chaotic illness experience (Frank, 2013). The lack of information about CFS in the medical field may exacerbate a patient's ability to process and understand their illness experiences. It has been argued that CFS therefore disrupts or dismantles the self and that by telling one's story, patients' lives can be reassembled or reconstructed (Frank, 2013; Robertson, 2017). It is often difficult to articulate what it means to be ill and research tells us that in order to better understand the illness experience - for both the sufferer and others interested in learning more - a narrative exploration can be beneficial (Robertson, 2017). This article therefore uses the method of "poetic representation" (Richardson, 1997) to provide a creative interpretation of participants' CFS narratives in order to better understand their experiences and help shape the discourse on wellbeing as it pertains to sufferers of this poorly understood illness.

\section{Aim}

The aim of this study was to explore women's narratives of dealing with CFS and understand their personal meanings of wellbeing and recovery. Women were chosen as the participant group for this study given the higher incidence of CFS in women compared to other genders. Through the means of poetic inquiry, we explore women's recovery journeys, that is, their journeys of recovering functional lives and attaining improved wellbeing in the face of a challenging CFS illness experience.

\section{Method}

\section{Participants}

This research study was approved by the Monash University Human Research Ethics Committee (MUHREC) prior to commencement. Advertisements soliciting interest to participate in the study were published in e-newsletters and social media avenues of wellness and wellbeing interest groups. The inclusion criteria were that adult women who had been diagnosed with CFS were eligible to participate in the study. To minimize ethics-related risks, certain demographics were excluded: minors; pregnant women; people in palliation; and those with cognitive impairments, medically diagnosed mental illnesses or intellectual disabilities.

Interested people contacted the first author via email to express interest in participating in the study and were then asked screening questions as per research inclusion criteria via telephone or email. If the participants satisfied the inclusion/exclusion criteria and gave informed consent, they were included in the study. The consent process involved reading an Explanatory Statement and signing a Consent Form. Participants were de-identified through the use of pseudonyms and include (with age and country of residence): Abigail (43, Canada); Alicia (53, Australia); Cassandra (65, USA); Daisy (46, England); Faith (36, Scotland); Iris (33, England); and Kayley (23, England).

\section{Interviews}

Because experiences of CFS are compounded by a lack of clear diagnostics and treatment procedures, an idiographic data collection and analytical method that would allow for detailed exploration of individuals' experiences, was deemed appropriate (Larkin et al., 2006). Semistructured interviews were conducted with participants, which served as intentional conversations yielding rich and detailed first-person accounts of participant experiences of CFS 
(Liamputtong \& Ezzy, 2005). The interviews typically lasted 60-75 minutes, with some taking up to 90 minutes. Demographic information was collected, including age and geographical location. Participants were typically asked to provide some background information about themselves, their illness, and describe what recovery meant to them, although each conversation followed its own path in accordance with the participants' stories. Interviews were transcribed verbatim, including non-verbal expressions such as laughter, long pauses, hesitation and other emotional cues, to assist in the analytical process (Smith et al., 2009).

\section{Poetic representation as a creative analytical method}

For this study, we transformed participants' transcripts into poetic representations. Poetic representation refers to poems that tell stories, in this case CFS illness stories (Faulkner, 2009, p. 19-21). Poetry is ideal for working with illness narratives as it mimics the fragments and broken narratives that emulate illness experiences. We treated the verbatim interview transcripts as source documents and restructured participants' words into poetic forms. By compressing the participants' transcripts into these forms, dense text becomes illuminated and focused. While the stories and words belong to the participants, the poetic representations were constructed by the researchers. Prendergast (2009) calls poetic representation an artistic practice within a research framework because it is "interested in creative language-based processes of constraint, synthesis, crystallization, image, and lyrical forms" (p. 561). Poetry can thus enable the curious mind to see beyond the "everyday" because we often listen more intently and can "creatively play with metaphor and image during analysis, and communicate with more liveliness and accuracy when representing data" (Cahnmann, 2003, p. 32).

The selection of poetic representation as a form of inquiry in this study was also partly driven by our own academic and personal interests in sociological approaches to understanding patient narratives and poetry as an artform. We thereby identify our own positionality in the research context and process (Corlett \& Mavin, 2018). The creative work of constructing the research poems took time and careful consideration. Words and transcripts were read and reread, silently and aloud, while condensing, compression and discussion occurred. With both researchers engaged in an iterative process (first individually, then together in a series of workshop-style meetings), the poems began to take shape over a period of time and multiple readings and review.

A key challenge that we faced in the poetry development process was balancing participants' raw words with our own creative and analytical roles as researcher-poets. In order to authentically represent our participants' words, we did not change word forms (e.g. tenses) in the poems, unless absolutely necessary, indicating alterations through the use of square brackets [ ]. Additionally, to maintain some chronicity in the narratives, we did not generally re-order the participants' words as they appeared in the interview transcripts. Lines and stanzas were parsed based on the separation of ideas and narratives in order to make sense of the data in a way that resonates with the rhythms of speech (Faulkner, 2009; Riessman, 2003).

In developing our poetic representations, we relied on several traditional creative tools employed in development of poetry, such as alliteration (to create rhythm), metaphors (for greater impact), and repetition (to highlight certain ideas). We applied the poetic method of 'listing', also known as 'catalogue verse', wherein several singular words or short phrases are written in succession to emphasize a specific point or add vividity and variety to a given topic (Cahnmann, 2003). We utilised other literary devices in the poetry creation such as the 'caesura', a rhythmical pause to convey the intensity of a feeling, sentiment, or idea (Literary Devices, 2019). The literary device of 'enjambment' was also applied, characterized by the continuation of lines 
without the use of punctuation between them to emphasize that recovery is not destination, but a journey. In addition, we carefully considered our use of punctuation to ensure that the poetic forms reflected the nuances of participants' words and experiences; for example, periods signify a sense of finality, whereas ellipses demonstrate an ongoing continuity of certain events or experiences.

\section{Analysis and Discussion}

While widely used qualitative analytical approaches such as thematic analysis is typically used to elucidate codes and themes from interview transcripts (Braun \& Clarke, 2013), Butler-Kisber (2010) argues that poetry can be 'clustered' in ways that provide greater analytical depth. In our data analysis, we therefore clustered various poetic representations together through a temporal lens, recognizing the notion of recovery as a journey and reflecting the importance of time (and changing perceptions of time) as a factor in participants' experiences of CFS. The following themes or poetic 'clusters', embedded in a temporal framework, emerged in our analyses:

- Downhill to diagnosis

- From diagnosis to despair

- From despair to hope

- Looking back to move forward

- And, now...

\section{Downhill to diagnosis}

This cluster of poems, Downhill to diagnosis, was based on the common experience of a progressive worsening of participants' health, followed by an eventual diagnosis of CFS; the accompanying confusion illustrated by the poem Kayley's body shuts down.

\section{Kayley's body shuts down}

When I was 12 years old

I was feeling very tired more and more and more...

People would be saying

"Oh go to bed, you are so tired"

When my mum would ask me

to do stuff around the house

I would say "I am too tired, I can' $t$ "

Everything started

to go downhill

I had blood tests

nothing seemed to be wrong

I thought I was imagining it

I looked normal...

"What's wrong with me?"

My body basically shut down.

My parents started trying to find out

what is wrong with me 
"Is she just depressed?"

"Is she just unhappy?"

I went to this clinic,

[They] diagnosed me with Chronic Fatigue Syndrome.

The above poem reflects the stress, confusion and blame that can arise in patients due to the lack of routine CFS diagnostic procedures. Repetition of the poignant question "what is wrong with me?" was very noticeable for us in Kayley's interview transcript. The poetic form highlights Kayley's discomfiture, self-blame and questioning. The dismissal by other people to just go to bed, as if her suffering was merely a temporary, ordinary tiredness seems to exacerbate Kayley's self-blame, and raises the question of whether it was all in her mind. The expression of one's body shutting down is also remarkable; as if the body were a shopfront, closing for business. This vernacular represents to us a sense of finality, an extended pause in the functioning of the body - the 'closed' sign appearing on the shopfront door.

Larun \& Malterud (2007) note that a challenging diagnostic journey and questioning of an illness's legitimacy can burden patients and impact their self-identity. This notion of legitimacy is illustrated in the following poem called Alicia, the fixer.

\author{
Alicia, the fixer \\ Apart from getting sick \\ I could figure most things out for myself \\ I could work out anything \\ if I worked hard enough at it \\ I could figure [it] out \\ I used to fix companies \\ but I couldn't fix myself.
}

The above poem demonstrates Alicia's struggle with reconciling her former identity as a heavily committed and effective problem-solver, with her new but confounding illness experience. While Alicia views herself as accomplished and able to solve complex issues, her words "I couldn't fix myself" imply a notion of a deficit self, rooted in the pathologizing idea that she is also, frustratingly for her, a problem to be solved. As Alicia remarks, while she could fix complex organizations with hard work and determination, it was impossible to repair her own body, herself; this loss of power to illness is discombobulating in a way that Robertson $(2017$, p. 17) describes as "estranging". In the same vein, the following poem, Daisy's yuppie flu highlights the lengths some patients with CFS go to, to find a treatment or cure for their condition.

\title{
Daisy's yuppie flu
}

Not being well my entire life

age of 13, I had chronic fatigue

"Yuppie flu"

it wasn't well acknowledged

There wasn't a lot of knowledge about it

There wasn't any real structure, treatment

[I tried] Chinese medicines

Chinese herbs

Acupuncture 
Craniosacral treatments

Chiropractor

Nothing like pacing regimes

The way doctors understand it now

I'd done loads of things

I got all my amalgam fillings taken out

I'd gone to loads of nutritionists

changed my diet

loads of vitamins

I had constant anxiety

depression from being ill

I'd work

I'd crash

The euphemism 'yuppie flu' to describe a debilitating chronic illness highlights the lack of social and medical understanding of CFS when Daisy was first diagnosed. In this poem, we use the literary device of 'listing' (Cahnmann, 2003) to highlight the variety of treatment modalities Daisy attempted to try and feel better; like a shopping list, she tries this treatment modality and then this and this. This technique of listing illustrates the clear sense of desperation in Daisy's efforts to regain her health. As Robertson (2017) explains, people often look to the health care system for empathy and help but frequently in the case of chronic and complicated illnesses such as CFS, the medical system is unable to provide that support. Indeed, difficulties associated with CFS diagnosis and treatment, as illustrated in this poem, often lead to patients feeling a sense of personal and social loss (Jelbert et al., 2010), as will be further discussed in the following poetic cluster.

\title{
From diagnosis to despair
}

This cluster of poems highlights the participants' somatic and emotional experiences of battling CFS. Frank (2013) notes the difficulty in telling a coherent illness narrative because life with a chronic illness is replete with "a series of present-tense assaults" (p. 11). The future is often hard to envisage when there is uncertainty, pain and chaos. Participants described suffering from a range of physical and emotional symptoms, which also cascaded into their social environments, as illustrated in the following poem, Abigail is bound.

\author{
Abigail is bound \\ Wheelchair-bound \\ House-bound \\ hopelessness \\ helplessness \\ anger \\ grief \\ depression \\ suicidal thoughts \\ isolated at home \\ without work \\ friends dropping like flies \\ they can't relate to it
}


intolerant to every food

sleeping three hours a night

nightmares and flashbacks

feeling as though

nothing will ever change.

In the above poem we delineate, through the use of poetic listing, the myriad of physical and emotional symptoms experienced by people with CFS. Abigail's symptomatology is varied and debilitating, affecting all areas of her life from an inability to eat, sleep, and even walk. The metaphor she uses, "friends dropping like flies" is a powerful reflection of her rapidly altered social relationships, as is the case with many CFS patients (Jelbert et al., 2010). In effect, the friends 'drop' Abigail, adding to her descent into depression and isolation. In ending this poem, we intentionally applied the punctuation of a period after the participant's words "nothing will ever change" to reflect a sense of finality and hopelessness; for Abigail, this is how it was going to be from now on.

The next poem also reflects the myriad of symptoms affecting people with CFS.

\section{Noises on Daisy's skin}

Very spacey

difficult to concentrate

drag myself to commute

lots of pain

noise quite painful

I could feel noises on my skin

pain in my joints

pain outside my body

stiffness

pain

muscle, joint pain

pain in my bones

migraines... digestive problems

debilitating tiredness; really, really tired

I could barely think

days where I couldn't get out of bed

swollen up, retained a lot of water

very, very anxious

very, very depressed

fuzzy thinking

very cold, freezing cold

all the time...

The above poem continues the theme of the multiple and variable symptoms associated with CFS affecting several of the body's organs and life processes, from digestive, skeletomuscular to nervous systems. We threaded Daisy's repeated use of the words "very" and "really" in her interview when constructing this poem, to attest to the aggravated symptoms she endured. The use of phrases "a lot of" or "lots of" seek to further amplify the intensity of felt symptoms. Repetition is also used to effect with the word "pain". As this word appeared several times 
during Daisy's interview transcript, it was thus embedded in the poem to convey the multiple levels on which this symptom was experienced. The feeling of pain outside the body is also noteworthy and illustrates that the lived experience of pain goes beyond physical symptomatology, and is also felt viscerally and perceptually. Similarly, the notion of feeling "noises on the skin" further exemplifies the overpowering physical discomfort and sensitivity that CFS brings. Other qualitative experiential research conducted with CFS patients also reports congruent accounts of hypersensitivity (e.g. Söderlund et al., 2000), as illustrated by the next poem.

\section{Cassandra hits a brick wall}

My skin hurt

to take a shower, the water hurt my skin

a lot of sound would hurt my hearing

so fatigued, like I was

dragging an elephant out of bed

exhausted, I'd wake up exhausted

I was like a 98 year old woman in my forties

I have to call and cancel again

I hated doing that

but I also hated being so tired

I couldn't

you hit a brick wall

you're fine,

you're fine,

you're fine,

then the next second,

you're not...

your brain shuts down

your body shuts down

you can hardly form a sentence

it's not like being tired

I had more energy running a marathon

the marathon stuff is within your control

you've built your body up

but the other stuff just catches you unaware

Cassandra's feelings of pain from normally benign everyday stimuli such as water and noise, echoes the hypersensitivity experienced by CFS patients, as previously discussed. The use of metaphors in this poem is particularly evocative. Analogizing her body with an elephant highlights the heavy burden of movement Cassandra experiences. The various points of comparison and contrast presented in this account also help to exemplify the lack of control and autonomy rendered by CFS. For example, Cassandra's comparison of herself with a 98-year old woman denotes rapid decay of her physical body. There is also an affecting contrast with running a marathon being deemed easier than enduring the CFS experience - because training can prepare one for the former, while the latter remains capricious. To magnify the unpredictability of symptom re-emergence, we utilized a combination of indentation, punctuation and the literary tool of caesura. The indentation (before "you're fine") followed by the caesura (depicted by a 
comma) seek to suggest a passage of time where Cassandra continues to feel reasonably well. The shock of symptom relapse and continuance is then captured through our use of ellipses when suddenly Cassandra is no longer "fine". As time passes with a chronic illness, participants also move forward with their illness and recoveries, and the next cluster of poems reflects a sense of optimism and hope for a better future.

\section{From despair to hope}

This cluster, From despair to hope, is centered around a pivotal moment, or series of moments that engendered a feeling of hope in the participants. Being faced with any chronic illness, let alone one that has no prescribed medical tests or treatments can often result in hopelessness for the future (Jelbert et al., 2010). In the following poem, we describe a participant's journey towards hope for improvement in her health and wellbeing.

\section{Kayley believes}

The doctors were saying

"you are not going to recover"

"there are no treatments"

I spent about six months

working on the way

I perceived my illness

and the world

and a lot of issues

and I got to a place where

I believed that I could get better

This poem points to a sense of agency and autonomy. After having been told, quite definitively, by authority figures that she would not get better, Kayley appears to have determinately 'walked her own path', possibly to prove the doctors wrong, but certainly with the self-belief to heal. As with other poems, there is a sense of movement and journey as noted by the words "I got to a place". This notion of illness as motion accords with Sontag's (1979) depiction of illness as travel or journey. The next poem continues the theme of movement towards healing and wellbeing.

\section{Fleur's joyful recovery}

I was looking for ways to help myself recover from chronic fatigue syndrome I was adamant no matter what, I was getting well I threw away all the horror stories of people with ME and started reading recovery stories to get some inspiration of what might help me I came across a book by Sasha Allenby called, "Joyful Recovery" and I thought, "Oh, joyful!"

"That sounds wonderful!" 
and I read that...

Her journey from CFS to full health

she had a very similar background to me,

been through a lot of same things

I [gave] myself permission to heal

We wake up,

we count all our ailments,

make sure they are all there,

present and correct,

then we go on...

When I came across this concept

of giving yourself permission to heal,

that made sense to me...

Fleur's account recapitulates the previous discussion on the determination to improve one's health and wellbeing. The idea of giving herself permission to heal symbolizes Fleur's sense of hope and agency for an alternate possibility for her life alongside an apparent refusal to accept her prognosis. In this poem, we again applied indentation and caesura to reflect the progression and passage of time in Fleur's morning routine. The ellipses after "then we go on" seeks to capture the continual cycle of waking up, counting and confirming the presence of ailments, going about your day, and repeating this process the following morning. Some may argue that this account resonates with the principles of positive psychology (Gable \& Haidt, 2005), as depicted by the lines, "throwing away of horror stories", imagining the possibility of a "joyful recovery", and the somewhat self-deprecating playfulness of Fleur ensuring her symptoms are "present and correct".

Chronic illness literature views hope as a "psychosocial resource", that by nature, is transcendent of possibilities, and can assist patients cope with their chronic illness (Duggleby et al., 2012, p. 1211). Furthermore, optimism and hope can often act as catalysts for people engaging in healthier behaviors, which in turn can be beneficial for chronic disease management (Schiavon et al., 2017). For this study's participants, a belief in hope and possibility for recovery contributed to changes in their behavioral patterns, thought processes, and self-identity, as discussed in the following cluster.

\title{
Looking back to move forward
}

This cluster is called Looking back to move forward because with illness narratives, as previously mentioned, there is often a sense of movement alongside the notion of temporality. On the journey through illness, patients may have the desire to move out of illness towards wellness acknowledging that the journey may be convoluted. The poems in this section demonstrate notions of movement, reflection, hope and growth using poetic devices such as pauses and breaks to reflect this sense of motion and change. As Frank (2013) explains, the illness journey is often a process of growth and self-education and these poems reflect that sense of change too.

\author{
Alicia's "hell, yeah" \\ Push on \\ other people depending on me \\ push through it
}


that whole dynamic isn't working for me the biggest challenge to not over stimulate my body

coffee, sugary crap pushing through tiredness

thinking if I get it done

I can relax

the way I was brought up

just "suck it up"

a large part of my current journey

has been working out

what I refer to as

"hell yeah, I want to do that"

picking my battles

simplifying my life

I was working in one of the most

stressful jobs imaginable

I just sucked it up

how toxic it was

so toxic!

like a silent invader...

So, listening to my body

and understanding what it needs

has been key

being ruthless about

not exposing myself to unnecessary stress

no time for people's "dramas and shit"

really understanding my body

what it needs and doesn't need

and ultimately

forgiveness and compassion

for others

for myself

the strategy was to remove

as many stressors

physical, emotional, mental

and flood my body

with nutrients, fresh air, salt

give it the optimal environment

in which to recover...

In this poem, there is a clear sense of movement; Alicia even uses the notion of a journey to demarcate and reflect a before and an afterwards. Looking back to reassess her life prior to the onset of her chronic illness, Alicia notes the constant pressure (or "push") she was under; the repetition of the term "push" highlighting that this was not "the optimal environment in which to recover". Frank (2013) and Sontag (1979) support the notion of illness as a journey, one which 
often emerges in hindsight but is also self-defining. As Alicia constructs her story of illness, we notice the way she positions herself as agentic, moving forward and "removing" herself from a damaging and unhealthy environment (other "people's dramas and shit") to a space and place of understanding and self-care; a progression that Frank (2013) alludes to as a "process of learning" through illness (p. 219). In the next poem, we notice that Daisy is on a similar journey and the term "push" is also used to reflect the way she previously did things; in what she describes as a "a perfect recipe for chronic fatigue syndrome".

\section{Daisy isn't finishing her novel... at least for now}

I was a very driven person

just not stopping

always wanting to do more

I used to compete, show jumping

that was really tiring and exhausting

I was also a music journalist

album launches or gigs late at night

more exhausting myself

I had undiagnosed dyslexia

that plays into being really exhausted

trying to learn things

causing headaches, anxiety at school

being told I wasn't trying hard enough

all a perfect recipe...

for chronic fatigue syndrome

I'm not as driven any more

I used to push myself

to do things that were exhausting

and make me feel ill

I wrote three quarters of a novel

It was really exhausting

I didn't find it enjoyable

[people] kept saying, "Finish this novel! Finish this novel!

then it can get published"

But, that's not why I'm writing a novel

I was writing it as a creative exploration

if I never feel like it again, I won't

this is who I am, and this is how

I need to live my life

for it to work for me

to be well

In this poem, Daisy moves forward from a space where she was constantly, debilitatingly "exhausted" (noting that variations of this word are repeated five times in her interview transcript), to a place that now "works for [her] to be well". The sense of motion in the story is further illuminated by the notions of being very "driven" at that time when she would constantly "push" herself. While there are often such pressures on the self, these expectations may also be from external sources. As the title Daisy isn't finishing her novel indicates, others were pressuring 
her to complete her unfinished manuscript. But in Daisy's story, like Alicia's, there is ultimately a sense of reflexive agency; as Daisy says, the novel was not written to please others but as a "creative exploration" which may or may not ever get finished. The possibilities of the unfinished novel sit in a future that Daisy will herself determine; a decision that also highlights her personal growth and acceptance. The notion of looking back to move forward and personal growth is also evident in the following poem.

\section{Fleur is grateful for CFS}

I believe my CFS came

from being adrenally fatigued

for a very long time

due to childhood traumas and depression

It made me realize that it was all that

that had made me unwell

and it was all that

that was going to help me get well

I didn't like my body

I felt it had been used and abused

I felt I was fat, even though I wasn't

I didn't feel pretty

I wasn't what I thought my friends were

I disliked the body I was in

and the person I was

I didn't feel like I was popular enough

I didn't feel that people liked me

I felt like I had to be somebody that I wasn't

Wasn't doing well enough

Wasn't earning well enough

I didn't feel enough

I didn't feel enough in who I was

I realized my life prior to getting CFS

was not healthy - mentally or physically

and even though CFS was horrendous,

I am actually grateful for it

because I was just surviving before

literally surviving, and that was all...

and now, I am thriving

it has taught me so much about life

we all think that you need to just get up

go to work, have 2.4 children

this ideal of earning money, having a nice car

doing all this stuff

that most of us are not happy doing...

having the illness has really changed

what I thought about life, about myself

what I want in life

I don't think life is just for surviving 
I think life is for thriving

to live in harmony with ourselves, each other, and the planet

In Fleur's transcript, we could not help noticing words such as "changed" and "taught" denoting personal growth from the illness experience. In looking back to reflect on her past, Fleur tells us - and, in the telling, also informs her own narrative - that "... it was all that that had made me unwell, and it was all that that was going to help me get well". Fleur thus moves her story forward from a position of feeling she was never enough to a life living in "harmony", not only with herself but with "each other, and the planet". We recognize that the social and cultural expectations that were a feature of her life until she came more to terms with CFS can be internalized through years of social conditioning. Indeed, so powerful are these expectations and narratives, particularly in Fleur's life story, that the word "enough" is repeated five times in the poem; not good enough, slim enough, pretty enough, successful enough, popular enough.

In casting the raw data into the above poetic representation, we also applied the repeated commencement of phrases with "I' to amplify Fleur's extensive reflections on a myriad of aspects of herself, her life, and the people around her. Now, Fleur has moved forward, with wisdom and even gratitude, making the perhaps surprising statement "even though CFS was horrendous, I am actually grateful for it". This sense of gratitude for a difficult illness experience is a notion with which Brett (2002) concurs, arguing that while suffering is terrible, it is nevertheless something that can be learned from in a creative and active way. In addition, Fleur's use of the expression " 2.4 children" suggests the rejection of social and cultural narratives that people may accept often unconsciously, without introspection that they may have desires different from the norms of getting a job, starting a family, or owning material possessions. The poem also reflects two further compelling and repeated words alluding to their potency; "surviving" and "thriving" which are used several times in the poem to great effect. Surviving chronic illness alone is not enough for Fleur; it is important in the here and the now, to thrive. This notion of moving from surviving to thriving in the present, leads to our final cluster of poems.

\section{And, now...}

In this final section, we present poems that speak of transformation, and progress to places very much grounded in a more positive present. As Frank (2013) explains, when people are ill, they "live simultaneously with both the threat of disintegration and the promise of reintegration", (pp. 212) and these poems illustrate the notion of recovery and reintegration that may be inspiring for others going through similar illness journeys. The following poem denotes a more peaceful and meditative present.

\section{Iris sustains her health}

I had a chance to meditate this morning a two-minute pause to set me up for the day

I swim again, sustain my health

in some ways, my life is even busier now

but in a much more balanced way

with being able to meditate, calm my system

being more embodied in my experience

rather than living in my head

I work now as a complementary therapist

coaching people with chronic illness 
my colleague and I created

Women's Wellness Circle

online and in person support

for women with chronic health problems

a circle where everyone connects

and reaches out for support

we run online courses and residential retreats

it has really taken off

women say "this is a complete lifeline for me

I am stuck in my flat, on my own, all the time

I don't know where I would be without this group

thank you, you are saving my life"

This poem highlights notions of an embodied peace, demonstrated in Iris's use of words such as "meditate", "calm" and "balanced". The poem also shows the "sustaining" actions that enable Iris to "swim again". The metaphor of swimming is one also drawn on by Prosser (2007) who explains that illness has a way of forcing the sufferer to take "two steps forward and one step back; always shocking the system whenever improvements show signs of plateauing; and always swimming against the tide ..." (p.199). Like Prosser, this poem also reflects the motions of swimming, a movement forward which may be hesitating at times, but it is nevertheless a progression.

Iris's story also highlights how reaching out to others can be rewarding; she describes the creation of a healing "circle where everyone connects"; where other women with chronic illnesses "reach out for support" in a way they report as a type of lifeline ("you are saving my life"). Indeed, reaching out to others while suffering, or having suffered, a chronic illness can be therapeutic. As Frank (2013) indicates "illness remains a nightmare in many ways, but it also becomes a possibility, especially for a more intimate level of connection with others" (p. 11). Connection with others is further highlighted in the following poem which relates Cassandra's journey to "now".

\section{Cassandra's week in Paris}

I can walk several miles

I can ride my bike, garden,

I don't have to cancel things

if I make plans with friends, I can keep them

we can go to a movie

my friends enjoy counting on me too

they understood before

but it's also a bummer

in the winters I carry my wood

I shovel snow

I feel strong and energetic

my little baby got married last May

I watched him grow up and go to college

and he married

he's six foot two, gorgeous, has a beautiful wife

I feel very blessed, I felt very blessed 


\section{I travelled to Paris}

my son, I met him in Paris

we had a week in Paris

we walked for miles every day...

Cassandra's account of a present where she can now fully connect with friends and family, also represents a "strong and energetic" woman who has the energy and vitality to chop and carry wood, and shovel snow. Not only does this poem illustrate the ways in which Cassandra has the strength to thrive, it also highlights her life's "blessings", as she reflects on successfully raising a family, demonstrated by her description of a "six foot two, gorgeous", newly-married, son, with whom she had the fortune to travel to Paris. For many people, overseas travel is a lifelong dream, particularly to the romantic city of Paris; for the unwell, any travel may seem like an almost impossible dream. Cassandra is understandably proud not only that she could meet her son for a "week in Paris" but that she could walk around the city "for miles every day". Cassandra's present story is an optimistic one filled with can do's, rather than recriminations for what she cannot do. Interestingly, the word "can" is repeated four times in Cassandra's narrative, in a way that is reminiscent of the story of the little engine that tries and tries to make its way up the mountain by repeating the mantra to itself "I think I can, I think I can", and is slowly, incrementally and ultimately, successful (Piper, 1930). The final poem in this article also uses a mountain climbing metaphor, both literally and figuratively.

\section{Fleur climbs a mountain}

I decided to walk up a mountain!

I thought this would either kill me or make me realize I am fully well that day, I walked up that mountain I didn't struggle any more than anyone else that was there the day after that, I was a bit achy but you would expect that after climbing a mountain after that, I was absolutely fine and that was my moment when I thought "it's gone" There are moments during your recovery where you can do the odd thing here and there but being able to walk up a mountain and feel fine two days later definitely, there is no ME left then I am an author now, mainly self-help based on what I have been through I am also a coach, a health coach living in health, harmony and happiness...

Fleur's account emphasizes the notion of the mountain as a metaphor, while also demonstrating the very practical challenges of successfully climbing a mountain; it is thus a fitting way to end 
the poems in this article. For the participants in this study and many people with chronic illnesses, the notion of climbing a mountain is a useful metaphor for grappling with their illness. Prosser (2007) describes his recovery from serious illness as similar to mountain climbing; like chronic illnesses, they seem insurmountable and can thus act as a powerful visual symbol for recovery from illness. Such metaphors are effective in helping us to better understand the stories of others who may have recovered or are going through their own illness journeys. While everyone with an illness story has their individual journey to navigate, people may recognize elements of their own story in these poems and reflect "that's my story. I am not alone" (Richardson, 1997, p. 33).

\section{Limitations and Implications}

As demonstrated in the thematic analysis and clustering of poems to analyze participants' stories of CFS in this study, the promise of poetic representation is that it vivifies participants' words bringing their experiences to life. There is legitimacy in undertaking research using poetic representation because it resonates with participants' speech styles, rhythms and words and this is highly relevant to a group of women suffering CFS, whose voices may otherwise be unheard, dismissed or overlooked (Evelyn, 2004; Richardson, 2003).

It is however important to distinguish between poetry as research inquiry and poetry as therapy. There is certainly value in the field of healing and psychological therapy through the creation of poetry (Croom, 2015; Hoffman, 2014), but poetic representation as a field of research inquiry should not be conflated with the technique of poetry as therapy to improve wellbeing (Prendergast, 2009, p. 563). We also acknowledge other limitations in this project e.g.: gender is obviously a factor in the lives of participants, however due to the scope of the article, we are unable to provide a gendered discussion of the participants' accounts of CFS. Further research could explore participants' stories of CFS through a feminist lens. In addition, there is scope for transforming people's illness experiences into poems through other intersectional lenses such as ethnicity, age or sexuality.

Other research implications include poetic representations that are co-created with participants, rather than researcher-constructed. There is also the possibility of research which involves collective poetic representations that collate a number of participant voices. In addition, poetic representation could be used to explore other illnesses or diseases. As Cahnmann (2003) argues, there is still a need for more poetic inquiry to form and inform a wider group of researchers to add further depth of knowledge to the field. Indeed, she notes that many outside the field of qualitative inquiry claim that poetry is not and cannot ever be "real" research; that it has little to contribute and that it is indeed, a "risky business" (Cahnmann, 2003, p. 30). We contend though that new forms of representation and analysis contribute to the field of research by offering new ways of seeing and understanding illness experiences, and concepts of wellbeing and recovery. Such an exploration not only holds therapeutic value for the patients themselves, but can also offer invaluable clinical insights into the illness experience for health professionals and other interested parties such as carers and family members.

\section{Concluding Remarks}

The poetic representations presented in this article shed light on the arduous illness experience of CFS. In the process of constructing poetry from interview transcripts, there emerged a larger story of progression from despair, to hope, to significant identity transformation. Through this work, our hope is to inspire further creative explorations of the patient experience, not only to offer a therapeutic outlet for patients, but to generate meaningful insights for driving 
improvements in patient care based on a more authentic and empathetic understanding of patient narratives.

\section{Acknowledgements}

We thank all the participants of this study for taking the time to share their stories, and generously letting us into their lives. We also thank late Dr Anske Robinson for her contributions to this research. The data presented in this article was originally collected as part of the first author's Ph.D. research funded by the (formerly) Australian Postgraduate Award scholarship. No other funding was obtained for the conduct of this study.

\section{Conflict of interest statement}

The authors report no conflicts of interest.

\section{Authors}

Mahima Kalla

Monash University

kallamahima@gmail.com

Margaret Simmons

Monash University

\section{Publishing Timeline}

Received 2 September 2020

Accepted 26 November 2020

Published 17 December 2020

\section{References}

Anthony, W. A. (1993). Recovery from mental illness: the guiding vision of the mental health service system in the 1990. Psychosocial Rehabilitation Journal, 16(4), 11-23. https://doi.org/10.1037/h0095655

Braun, V., \& Clarke, V. (2013). Successful qualitative research: A practical guide for beginners. Sage Publications.

Brett, D. (2002). Eating the underworld: A memoir in three Voices. [Doctoral dissertation, Victoria University]. http://vuir.vu.edu.au/15430/1/Brett_2002_compressed.pdf

Butler-Kisber, L. (2010). Qualitative Inquiry: Thematic, Narrative and Arts-informed Perspective. Sage Publications. https://doi.org/10.4135/9781526435408

Cahnmann, M. (2003). The Craft, Practice, and Possibility of Poetry in Educational Research. Educational researcher, 32(3), 29-36. https://doi.org/10.2307/3699832

Corlett, S., \& Mavin, S. (2018). Reflexivity and researcher positionality. In C. Cassell A. Cunliffe \& G. Grandy G (Eds). The Sage handbook of qualitative business and management research methods (pp.377-89). Sage Publications. https://doi.org/10.4135/9781526430212.n23

Cornes, O. (2011). Living with CFS/ME (Commentary). BMJ. 342 https://doi.org/10.1136/bmj.d3836

Croom, A. M. (2015). The practice of poetry and the psychology of wellbeing. Journal of Poetry Therapy, 28(1), 21-41. https://doi.org/10.1080/08893675.2015.980133

Duggleby, W., Hicks, D., Nekolaichuk, C., Holtslander, L., Williams, A., Chambers, T. \& Eby, J. (2012). Hope, older adults, and chronic illness: a metasynthesis of qualitative research. Journal of Advanced Nursing, 68(6), 1211-1223. https://doi.org/10.1111/j.1365-2648.2011.05919.x

Eger, R., \& Maridal, J. H. (2015). A statistical meta-analysis of the wellbeing literature. International Journal of Wellbeing, 5(2), 45-74. https://doi.org/10.5502/ijw.v5i2.4

Evelyn, D. (2004). Telling Stories of Research. Studies in the Education of Adults, 36(1), 86-110.

Faulkner, S. L. (2009). Poetry as Method: Reporting Research through Verse. Left Coast Press. 
Frank, A. W. (2013). The wounded storyteller (2nd ed.). University of Chicago Press.

Gable, S. L., \& Haidt, J. (2005). What (and Why) Is Positive Psychology. Review of General Psychology, 9(2), 103-110. https://doi.org/10.1037/1089-2680.9.2.103

Harvey, S., \& Ismail, K. (2008). Psychiatric aspects of chronic physical disease. Psychiatric Aspects of General Medicine, 36(9), 471-74. https://doi.org/10.1016/j.mpmed.2008.07.003

Hoffman, L. (2014). The therapist's use of poetry in therapy: Deepening relationship and understanding through creativity. In M. Heery (Ed.), Unearthing the moment: Mindful applications of existential humanistic and transpersonal psychotherapy (pp. 208-221). Tonglen Press.

Jelbert, R., Stedmon, J., \& Stephens, A. (2010). A qualitative exploration of adolescents' experiences of chronic fatigue syndrome. Clinical Child Psychology and Psychiatry, 15(2), 267-283. https://doi.org/10.1177/1359104509340940

McNaught, A. (2011). Defining wellbeing. In Knight, A. \& McNaught, A. (Eds.). Understanding wellbeing: An introduction for students and practitioners of health and social care (pp.7-23). Lantern Publishing.

Larkin, M., Watts, S., Clifton, E. (2006). Giving voice and making sense in interpretative phenomenological analysis. Qualitative Research in Psychology, 3(2), 102-120.

Larun, L., \& Malterud, K. (2007). Identity and coping experiences in Chronic Fatigue Syndrome: A synthesis of qualitative studies. Patient Education and Counselling, 69(1-3), 20-28. https://doi.org/10.1016/j.pec.2007.06.008

Liamputtong P., \& Ezzy D. (2005). Qualitative Research Methods (2nd ed). Oxford University Press.

Liberman, R. P., \& Kopelowicz, A. (2005). Recovery from schizophrenia: A concept in search of research. Psychiatric Services, 56(6), 735-742. https://doi.org/10.1176/appi.ps.56.6.735

Literary Devices. (2019). Caesura. https://iterary-devices.com/content/caesura/

McLeod, K. (2017). Wellbeing machine: How health emerges from the assemblages of everyday life. Carolina Academic Press.

Mueser, K., Corrigan, P., Hilton, D., Tanzman, B., Schaub, A., Gingerich, S., Essock, S. M., Tarrier, N., Morey, B., Vogel-Scibilia, S., Herz, M.I. (2002). Illness management and recovery: a review of the research. Psychiatric Services, 53(10), 1272-84. https://doi.org/10.1176/appi.ps.53.10.1272

Piper, W. (1930). The little engine that could. Grosset \& Dunlap.

Prendergast, Monica. (2009). Poem Is what? Poetic inquiry in qualitative social science. International Review of Qualitative Research, 1(4) 541-568. https://doi.org/10.1525/irqr.2009.1.4.541

Prosser, J. (2007). Visual mediation of critical illness: an autobiographical account of nearly dying and nearly living. Visual Studies, 22(2), 185-199. https://doi.org/10.1080/14725860701507263

Richardson, L. (1997). Fields of Play (Constructing an Academic Life). Rutgers University Press.

Richardson, L. (2003). Poetic Representation of Interviews. In J.F. Gubrium \& J.A. Holstein (eds.) Postmodern Interviewing. (pp. 187-201). Sage Publications.

Riessman, C. (2003). Narrative analysis. In M.S. Lewis-Beck, A. Bryman and T. Futing Liao, (eds.) The Sage encyclopedia of social science research methods. (Vol. 3, pp. 705-709). Sage.

Robertson, R. (2017) "Undiscovered countries": An introduction to Shaping the fractured self. In H.T. Johnson (ed.) Shaping the fractured self: poetry of chronic illness and pain. (pp. 11-17). UWA Publishing.

Schiavon, C. C., Marchetti, E., Gurgel, L. G., Busnello, F. M., \& Reppold, C. T. (2017). Optimism and hope in chronic disease: A systematic review. Frontiers in Psychology, 7(2022), 1-10. https://doi.org/10.3389/fpsyg.2016.02022

Secker, J., Membrey, H., Grove, B., \& Seebohm, P. (2002). Recovering from illness or recovering your life? Implications of clinical versus social models of recovery from mental health problems for employment support services. Disability \& Society, 17(4): 403-418. https://doi.org/10.1080/09687590220140340

Slade, M., Amering, M., Farkas, M., Hamilton, B., O'Hagan, M., Panther, G., Perkins, R., Shepherd, G., Tse, S., Whitley, R. (2014). Uses and abuses of recovery: implementing recovery-oriented practices in mental health systems. World Psychiatry, 13(1), 12-20. https://doi.org/10.1002/wps.20084

Smith, J., Flowers, P., \& Larkin, M. (2009). Interpretative phenomenological analysis: Theory, method and research. SAGE Publications. 
Söderlund, A., Skoge, A. M., Malterud, K. (2000). "I could not lift my arm holding the fork": Living with chronic fatigue syndrome. Scandinavian Journal of Primary Health Care, 18(3), 165-169. https://doi.org/10.1080/028134300453377

Sontag, Susan. (1979) Illness as metaphor. University of Michigan.

Sweetman, E., Noble, A., Edgar, C., Mackay, A., Helliwell, A., Vallings, R., Ryan, M., \& Tate, W. (2019). Current research provides insight into the biological basis and diagnostic potential for Myalgic Encephalomyelitis/Chronic Fatigue Syndrome (ME/CFS). Diagnostics, 2019(9), 1-14.

https://doi.org/10.3390/diagnostics9030073 